\title{
LUDO-INFORMÁTICA NO COTIDIANO ESCOLAR COM A CIBERCULTURA
}

\author{
COMPUTER INLITERACY SCHOOL WITH CYBERCULTURE \\ Cláudio Joaquim dos Santos Braga \\ Universidade Federal do Rio de Janeiro (UFRJ) \\ ORCID: 0000-0002-4060-7435 \\ Data de submissão: 20/02/2019 \\ Data de aprovação: 05/04/2019
}

\section{RESUMO}

Nos dias atuais, somos sabedores da importância de incorporar as tecnologias digitais no cotidiano escolar, porém, em muitas realidades, essa ferramenta não é incluída como um recurso educativo. Neste trabalho, queremos ressaltar que a adoção dessas novas tecnologias no cotidiano escolar é de grande importância pedagógica e social, fazendo-nos refletir sobre práticas adequadas para o uso de cada recurso tecnológico ou uma integração de recursos. Neste contexto das tecnologias digitais, está a ludo-informática, que trabalha o aprendizado através dos jogos digitais. A ludoinformática possibilita que o lúdico se integre ao ambiente escolar, trazendo novos cenários de educação, pois a a pessoa, a partir do momento em que é estimulada, seja uma criança, um adulto ou uma pessoa com deficiência, alcançará um novo estado da arte, despertando em sua mente novas potencialidades.

Palavras-chaves: Ludo-informática. Tecnologias digitais; Cotidiano escolar. Cibercultura. Educação.

\begin{abstract}
Nowadays, we are aware of the importance of incorporating digital technologies in everyday school, but in many realities this tool is not included as an educational resource. In this work, we would like to emphasize that the adoption of these new technologies in the school routine is of great pedagogical and social importance, making us reflect on appropriate practices for the use of each technological resource or an integration of resources. In this context of digital technologies, there is computer science, which works through digital games. The ludo-informatics allows the playful to integrate into the school environment, bringing new educational scenarios, since the person, from the moment it is stimulated, whether a child, an adult or a person with a disability, will reach a new state of art, awakening in your mind new potentialities.
\end{abstract}

Keyword: Ludo-informática; Digital technologies; Daily school; Ciberculture, Education 


\section{INTRODUÇÃO}

Estamos no ano de 2019 e sabemos que a tecnologia, apesar de seu constante avanço, ainda não está presente em todas as realidades escolares de nosso país INEP (2016) . Nesse mundo cada vez mais globalizado, o mais importante não é como adquirir informações, mas sim como trabalhar essa informação de maneira crítica, pois é surpreendente a velocidade das tecnológicas que nos envolvem e, em muitos casos, não conseguimos nos desconectar de tantas informações que nos chegam de diversas formas. Nossos novos alunos, principalmente, já têm em seu cotidiano a tecnologia incorporada em cada dia de sua vida e, em muitos casos, eles, por meio da tecnologia, já são autores participativos da criação de novos conteúdos, participando de redes sociais e colaborativas (TORRES, 2004, p. 3) em que vão além da observação e assim participam de maneira ativa e direta.

Já os professores necessitam de uma formação continuada para se adaptar a essa constante evolução que se entranha muitas vezes sem permissão no dia-a-dia escolar (CARVALHO; CAMPOS JUNIOR; SOUZA, 2019, p. 9). No cenário onde a tecnologia está disponível, devemos nos preocupar como devemos trabalhar com ela de maneira pedagógica, já que estamos envoltos em uma cibercultura em nosso cotidiano.

Hoje não cabe mais uma educação bancária criticada por Freire (FREIRE, 2014), o perfil do docente obrigatoriamente mudou, mas ainda temos realidades em que vemos salas de aulas como em séculos passados em que o professor é o protagonista e os alunos, de maneira passiva e quietos, assistem às aulas, muitas vezes, interromper o professor para uma simples pergunta.

Como conviver com essa realidade, se o nosso cotidiano está envolto em tecnologia que nos fornece informações em tempo real a cada instante e nos tira dúvidas de qualquer assunto com poucos cliques ou perguntas verbais em diversos aparatos tecnológicos? O professor, em definitivo, não é mais o dono do saber, o senhor da memorização; os computadores são melhores do que qualquer ser humano nessa categoria.

A velocidade das novidades tecnológicas que nos envolvem é surpreendente. Nós nos acostumamos e, em muitos casos, não conseguimos nos desconectar dos aparatos celulares, televisores e informações que nos chegam a cada instante.

Quando a tecnologia está disponível devemos nos preocupar como poderemos trabalhar com ela de maneira pedagógica em nosso cotidiano, inclusive com alunos deficientes (ROTTA; BRIDI FILHO; BRIDI, 2018, p. 101). Importante informar que o computador e muitos aparatos tecnológicos não foram criados para a educação; ela apenas se apropriou dessas ferramentas e deu um uso pedagógico para cada equipamento.

Inegavelmente, os computadores são ferramentas valiosas para a relação ensino e aprendizagem, mas, durante muitos anos, antes mesmo da utilização do computador no ensino, educadores utilizavam o lúdico, descentralizaram a pedagogia centrada no professor e deram ao aluno um nível de protagonista. Podemos citar alguns autores que valorizavam o lúdico e o aprendizado dos alunos: Piaget (ALMEIDA; SHIGUNOV, 2000 p. 70), Vygotsky (SCHWARTZ, 2014, p. 177), Wallon (CARVALHO, 1998, p. 47), Dewey (ALBUQUERQUE; FELIPE; CORSO, 2019, p. 168), Froebel (KISHIMOTO, 2006, p. 453), Decroly (ALMEIDA; LEVY, 2013, p. 11), Kishimoto (FORTUNA, 2018, p. 68), Freinet (BARROS, 2017, p. 41), Rousseau (ANDRADE; ANDRADE; LEAL, 2019, p. 303), Pestalozzi (OLIVEIRA, 2017, p. 7), Montessori (BARREIROS, 2018, p. 36), 
Winnicott (FARIA; DIETRICH; GOMES, 2016, p. 64), Adriana Friedman (PERES, 2004, p. 38), Papert (CASTRO; MOURÃO, 2016, p. 8). Esses autores defendem o uso do lúdico como a prática educacional no sentido de um desenvolvimento pleno do cognitivo de nossos alunos, permitindo a construção de seu conhecimento.

Uma maneira atual de usar o lúdico no cotidiano escolar se faz pelo uso de jogos computacionais, que, por meio de desafios ou regras, exibem conteúdos, consolidando conhecimentos com ou sem a participação ativa do professor, professor que em muitos casos atua como mediador; em geral, esse uso é restrito a um aluno por computador, podendo ser em dupla. Propomos, através deste estudo, investigar a união do lúdico a aparatos tecnológicos, que denominamos de ludo-informática, pois, com brincadeiras, podemos desenvolver atividades que trabalhem as áreas cognitivas e sensoriais de nossos alunos, seu aprendizado colaborativo (SANTOS; CHIOTE, 2016, p. 6-7), possibilidades de mobilidade, acessibilidade e interação social.

O objetivo deste estudo é investigar, via pesquisa bibliográfica, a ludo-informática como um dispositivo no cotidiano escolar na cibercultura. Os objetivos secundários: investigar, via pesquisa bibliográfica, o uso do lúdico associado a jogos de computador; investigar possibilidades de softwares e hardwares que permitam que alunos com deficiência física participem das atividades lúdicas com a turma, participando com os mesmos equipamentos e softwares; avaliar a ludo-informática como dispositivo.

\section{REFERENCIAL TEÓRICO}

Vivemos em um país de extensão continental e com desigualdades extremas em que temos escolas que além de não possuírem computadores, sequer possuem energia elétrica, como afirma relatório do INEP (2016, p. 7) .

[...] As escolas que oferecem anos iniciais do ensino fundamental $71,3 \%$ das escolas de educação básica $(132,7 \mathrm{mil})$ oferecem alguma etapa do ensino fundamental. Dessas, 116,3 mil oferecem os anos iniciais (...) Na zona rural, 9,9\% das escolas não possuem energia elétrica, $14,7 \%$ não têm esgoto sanitário e $11,3 \%$ não têm abastecimento de água. Na zona urbana, esses percentuais são $0,0 \%$ (apenas 9 escolas), $0,3 \%$ e $0,2 \%$, respectivamente.

As escolas do último grupo estão inseridas na cibercultura, uma vez que a maioria delas vive em uma cultura em que a tecnologia faz parte do dia-a-dia. Os alunos já participam de redes sociais e colaborativas e não se identificam com uma educação bancária, fazem questão de comentar seus pensamentos e participam muitas vezes construindo saberes na Cibercultura.

Sobre o conceito de Cibercultura, citamos Lévy (2010, p. 17) "[...] Quanto ao neologismo "cibercultura", especifica aqui o conjunto de técnicas (materiais e intelectuais), de práticas, de atitudes, de modos de pensamento e de valores que se desenvolvem juntamente com o crescimento do ciberespaço". Nesse ciberespaço, onde a informação flui de maneira ininterrupta com um volume cada vez maior de informações e conhecimentos, nós nos vemos em uma realidade de uma frase que foi atribuída ao filósofo grego Sócrates: "Só sei que nada sei" (LEMOS, 2016, p. 19). Essa afirmação não era uma frase simplória ou de simplicidade e sim de sabedoria, pois nunca saberemos tudo sobre tudo que há para conhecer.

Freire (2014) afirma, e concordamos com isso, que "professor é um ser inacabado e consciente de seu inacabamento"; por isso, devemos sempre estar em constante atualização e cientes que nunca saberemos tudo. Freire também criticou a "pedagogia 
bancária", em que o aluno não é um mero receptor de informações e o professor o dono do saber absoluto e incontestável; sabemos, nas palavras dele, que "temos que respeitar a cultura de nosso educando", valorizando seus valores e inserindo itens do seu dia-a-dia e sua cultura no cotidiano escolar.

Vivenciamos hoje uma cultura digital, com o advento da informática e isso mudou em muitos casos o perfil dos nossos novos alunos; segundo Prensky (2010), eles são considerados "nativos digitais" e os professores "imigrantes digitais". Sendo assim, eles possuem mais abertura e facilidade para a incorporação e utilização de novas tecnologias em sala de aula, sendo um desafio grande para muitos educadores que, independentemente das formações continuadas existentes, continuam aplicando suas aulas como em séculos passados. A formação continuada é sempre um tema recorrente e importante na pedagogia, muitos educadores já se posicionaram sobre isso. Inclusive, no Brasil, houve um Manifesto no ano de 1932, assinado por Anísio Teixeira e outros educadores, que, entre outros assuntos, colocou como prioridade a formação continuada dos professores para uma educação universal de boa qualidade.

\subsection{As novas tecnologias digitais na ludo-informática}

Cysneiros em sua resenha, citando um texto de Papert, que desenvolveu a teoria construcionista baseada na teoria construtivista de Piaget, ilustra como em muitos casos, apesar da tecnologia educacional avançar, muitas aulas continuam sendo aplicadas como em séculos passados: "Conta que se médicos e professores do século dezenove nos visitassem hoje, teriam reações bem diferentes. Os médicos não reconheceriam as atuais salas de cirurgia, mas os professores se sentiriam à vontade se entrassem numa sala de aula cem anos depois" (CYSNEIROS, 1999).

Hoje em dia, em salas de aulas que utilizam a tecnologia, ao navegar na Internet para realizar uma pesquisa escolar, muitas vezes o aluno utiliza-se de ambientes digitais chamados de hipertexto, para complementar seu conhecimento que, em muitos casos, levam para uma complementação em outra disciplina independente da primeira que originou a pesquisa. Esse ciberespaço amplia nossa visão de conhecimento específico e especializado. Completamente contrário a um ensino cartesiano, ele nos traz, em alguns casos, novos conhecimentos que se contrapõem a conhecimentos antigos ou já consolidados. Houve uma época em nossa história, durante o positivismo, em que a ciência era algo inquestionável, uma verdade absoluta; hoje vivemos na era da incerteza, da complexibilidade, em que uma disciplina isolada já não é o suficiente para expressar nossa realidade, por isso nos vemos constantemente obrigados a trabalhar um assunto sob o olhar da transdisciplinaridade (FERRARI, 2008).

Sabemos o valor da formação continuada e não nos cabe recorrer sobre o uso correto e a importância do uso da tecnologia na educação, mas, antes de todos esses aparatos, diversos educadores utilizavam o lúdico como ferramenta para despertar o conhecimento, interesse, participação, socialização e levar o aluno a construção de seu conhecimento. A palavra lúdico tem como origem etimológica a palavra em latim ludus que significa brincar.

Segundo Almeida (2003, p. 23),

Pestalizzi (1946-1827), graças a seu espírito de observação sobre o progresso do desenvolvimento psicológico dos alunos e sobre o êxito ou o fracasso das técnicas pedagógicas empregadas, abriu um novo rumo para a educação moderna. Segundo ele, a escola é uma verdadeira sociedade, na qual o senso de responsabilidade e as 
normas de cooperação são suficientes para educar as crianças, e o jogo é um fator decisivo que enriquece o senso de responsabilidade fortifica as normas de cooperação.

Froebel (1782-1852), discípulo de Pestalozzi, estabelece que a pedagogia deve considerar a criança como atividade criadora e despertar, mediante estímulos, suas faculdades próprias para a criação produtiva. Na verdade, com Froebel se fortalecem os métodos lúdicos na educação. O grande educador faz o jogo uma arte, um admirável instrumento para promover a educação para as crianças. A melhor forma de conduzir a criação à atividade, à auto-expressão e à socialização seria por meio dos jogos. Tal teoria froebeliana realmente determinou os jogos como fatores decisivos na educação das crianças.

Indiscutivelmente, o lúdico é uma ótima ferramenta que agrega recursos à educação e, nos dias atuais, os jogos educativos computacionais despertam cada dia mais o interesse de nossos alunos. Esses jogos computacionais podem ser utilizados diretamente nos dispositivos tecnológicos em um mundo virtual com inúmeras possibilidades ou vinculados ao mundo real através da realidade aumentada, muito utilizada por profissionais de marketing, mas que está cada dia mais incorporando-se no processo educativo ou através de equipamentos que expandem o uso do hardware tradicional, indo além de um teclado, mouse ou monitor.

O lúdico e a interação social podem ajudar no aprendizado, possibilitando que crianças e adultos com menos experiência possam ser auxiliadas, ensinadas de maneira colaborativa/participativa para realizar um objetivo. É importante observar que o computador também possibilita que o aluno, com o auxílio de Ambientes Virtuais de Aprendizagem, com uma orientação específica, trabalhe a "Zona de Desenvolvimento Proximal" apresentada por Vygotsky (2007), trabalhando e interagindo com seus colegas, denotando que o aluno individual e coletivamente desenvolve aprendizados que ampliam sua forma de pensar e de conceber o mundo.

Designaremos de ludo-informática como dispositivo no cotidiano escolar com a cibercultura o uso de equipamentos que possibilitem a integração de atividades lúdicas ao uso de computador e um ambiente que permita, quando possível, a participação de alunos com deficiência física nas mesmas atividades e equipamentos, não negando as deficiências, mas valorizando as habilidades; por isso vemos a ludo-informática como um dispositivo útil para nosso cotidiano escolar na cibercultura.

Concordamos com a visão de dispositivo de Ardoino, citado por Santos; Alves (p. 129): "uma organização de meios materiais e/ou intelectuais, fazendo parte de uma estratégia de conhecimento de um objeto" (ARDOINO, 2003, p. 80).

\section{METODOLOGIA}

Utilizaremos como metodologia a análise de documentos através de revisão bibliográfica do estado da arte e escuta sensível.

\section{CONSIDERAÇÕES FINAIS}

Acreditamos que o lúdico, associado à tecnologia, permite a participação ativa dos professores e alunos na construção do conhecimento e atividades educativas 
efetuadas, permitindo também (respeitando os limites e possibilidades) a integração de alunos com limitações físicas, que poderão utilizar as mesmas atividades de forma igual com seus colegas, com base nas construções tecnológicas disponíveis para as atividades lúdicas.

É necessário aproveitar os recursos tecnológicos para unir, integrar, socializar e compartilhar conhecimentos, permitindo que o aluno seja usuário e autor de conteúdos e atividades, participando sempre de forma ativa, apoderando-se dos recursos para um uso educativo dessas ferramentas tecnológicas.

Embora não seja tratado aqui, é preciso continuar investigando o uso do lúdico associado a jogos de computador que possibilitem que alunos com deficiência participem das atividades lúdicas com a turma, participando com os mesmos equipamentos e softwares; pois a ludo-informática como cultura traz novas possibilidades de interação e de extensão cognitiva. Existem algumas pesquisas sobre o assunto, denotando a magia que envolve os jogos digitais na educação, reiterando o papel da lufo-informática na educação integral.

Concluímos que o lúdico, como tecnologia educacional, possibilita atividades que, estruturadas pedagogicamente, têm grande importância, colaborando na relação ensino e aprendizagem do aluno.

\section{REFERÊNCIAS}

ALBUQUERQUE, Simone Santos de; FELIPE, Jane; CORSO, Luciana Vellinho (orgs.). Para Pensar a Docência na Educação Infantil. Rio Grande do Sul : 2019. Universidade Federal do Rio Grande do Sul; Porto Alegre : Evangraf, 2019. ISBN 978-85-201-0077-7. Disponível em: https://www.lume.ufrgs.br/bitstream/ handle/10183/189727/001090381. pdf?sequence=1\&isAllowed=y\#page=160. Acesso em: 19 abril 2019.

ALMEIDA, Paulo Nunes de. Educação lúdica : técnicas e jogos pedagógicos. 11.ed. São Paulo : Loyola, 2003.

ALMEIDA, Berenice de; LEVY Gabriel. Brincadeiras e brincadeirinhas : uma experiência de formação de professores pelo Brasil. Música na Educação Básica. Brasília: 2013. Disponível em: http://www.abemeducacaomusical.com.br/revistas_ meb/index.php/meb/article/view/137/59. Acesso em: 19 abr. 2019.

ALMEIDA, Ana Cristina Pimentel C. de; SHIGUNOV, Viktor. A atividade lúdica infantil e suas possibilidades. Revista da Educação Física / UEM. Maringá, v. 11, n. 1, p. 69-76, 2000. Disponível em: <https://docs.google.com/viewerng/viewer?url=http:// eduem.uem.br/ojs/index.php/RevEducFis/article/viewFile/3793/2608>. Acesso em: 19 abril 2019.

ANDRADE, Graciele; ANDRADE, Graciela Coelho; LEAL, Ana Lúcia. Educação emocional no ensino infantil: uma perspectiva a partir do lúdico no teatro do oprimido de Augusto Boal. Revista Educação e Emancipação, São Luís, v. 12, n. 1, jan./abr. 2019. DOI: http://dx.doi.org/10.18764/2358-4319.v12n1p297-316. Disponível em: <http://www.periodicoseletronicos.ufma.br/index.php/reducacaoemancipacao/article/ view/10757/6241>. Acesso em: 20 abril 2019.

BARREIROS, Renata Ballego. Análise da educação ambiental lúdica: estudo de caso no ensino fundamental I. 2018. 82 f. Dissertação (Mestrado em Formação 
Científica, Educacional e Tecnológica) - Universidade Tecnológica Federal do Paraná, Curitiba, 2018. Disponível em: http://repositorio.utfpr.edu.br:8080/jspui/

bitstream/1/3313/1/CT_PPGFCET_M_Barreiros\%2c\%20Renata\%20Ballego_2018.pdf. Acesso em: 20 abril 2019. Link idēntificador: http://repositorio.utfpr.edu.br/jspui/ handle/1/3313.

BARROS, Cecília Georgina Domingues Gonçalves. Alunos com perturbação do espetro do autismo (PEA) e bullying em contexto escolar. 2017. 66f. Dissertação (Mestrado em Ciências da Educação - Educação Especial). Universidade Fernando Pessoa, 2017. Disponível em: https://bdigital.ufp.pt/bitstream/10284/6521/1/DM_ Cec\%C3\%ADlia\%20Barros.pdf. Acesso em: 18 dez. 2018.

CARVALHO, Clecilene Gomes de; CAMPOS JUNIOR, Dejanir José; SOUZA, Gleicione Aparecida Dias Bagne de. Neurociência: uma abordagem sobre as emoções e o processo de aprendizagem.. Revista da Universidade Vale do Rio Verde. v. 17, n. 1, jan./jul. 2019 Disponível em: http://periodicos.unincor.br/index.php/ revistaunincor/article/view/5619/pdf_900. Acesso em: 20 abr. 2019. DOI: http://dx.doi. org/10.5892/ruvrd.v17i1.5619

CASTRO, Flavia Neves de Oliveira; MOURÃO, Nadja Maria. Comunicação e a inclusão de surdos: uma proposta do jogo Librário em aplicativo para o ensino. Simpósio - Tecnologias e Educação a Distância no Ensino Superior. 2018. Universidade do Estado de Minas Gerais (UEMG). Disponível em: <http://revista. uemg.br/index.php/Simposioteceedadistnoenssuperior/article/view/3036/1724>. Acesso em: 20 abril 2019.

CYSNEIROS, Paulo Gileno. Resenha crítica. Revista Brasileira de Informática na Educação. n.5, 1999. Disponível em: http://www.br-ie.org/pub/index.php/rbie/article/ viewFile/2284/2046. Acesso em: 20 abril 2019.

SANTOS,Edmea; ALVES, Lyn (orgs.) Práticas pedagógicas e tecnologias digitais. Rio de Janeiro : E-papers, 2006. 328 p.

FARIA, Luiz Henrique Portela; DIETRICH, Ana Maria; GOMES, Vivilí Maria Silva. O projeto batuclagem e a educação ambiental por meio do brincar: abordando o lúdico no ensino de ciências. R. Labore em Ensino de Ciências, Campo Grande, v.1, n. especial p. 61-76, 2016. ISSN 2526-785X. Disponível em: <http://www.seer.ufms.br/ ojs/index.php/labore/article/view/5475/pdf_16>. Acesso em: 20 abril 2019.

FERRARI, Márcio. Edgar Morin, o arquiteto da complexidade. Sociólogo francês propõe a religação dos saberes com novas concepções sobre o conhecimento e a educação. Publicado em 01 de outubro de 2008. Revista Online Nova Escola. Disponível em: <https://novaescola.org.br/conteudo/1391/edgar-morin-o-arquiteto-dacomplexidade>. Acesso em: 19 abril 2019.

FORTUNA, Tânia Ramos . Brincar é aprender. In: GIACOMONI; Marcello; PEREIRA, Nilton Mullet. (Org.). Os jogos e o ensino de história. 1 ed. Porto Alegre: Editora da UFRGS, 2018, v. 1, p. 1-129.

FREIRE, Paulo. Pedagogia da autonomia: saberes necessários à prática educativa. São Paulo : Paz e Terra, 1999.

KISHIMOTO, Tizuko Morchida. Educação infantil no Brasil e no Japão: acelerar o ensino ou preservar o brincar? Revista Brasileira de Estudos Pedagógicos. 
Brasília, DF, Brasil. 2006. e-ISSN: 2176-6681. Disponível em: <http://rbep.inep.gov.br/ index.php/rbep/article/view/519/502>. Acesso em: 19 abril 2019.

LÉVY, Pierre.Cibercultura. 3.ed. São Paulo : Ed. 34, 1999. 272 p.

LEMOS, Maria Teresa Turibio Brittes (org.). Religião, violência e exclusão. Rio de Janeiro: 7 Letras, 2016. 196p.

OLIVEIRA, Francisca Edineide de. O lúdico como instrumento de aprendizagem no $1^{\circ}$ ano do Ensino Fundamental. 2017. 23f. Trabalho de Conclusão de Curso (Graduação em Pedagogia), Centro de Educação, Universidade Federal do Rio Grande do Norte, Caraúbas, 2017. Disponível em: https://monografias.ufrn.br/jspui/ bitstream/123456789/5602/3/0\%20I\%C3\%BAdico\%20como\%20instrumento\%20 de\%20aprendizagem_Artigo_2017.pdf. Acesso em: 20 abril 2019.

PERES, Regina Cristiane N. C. O lúdico no desenvolvimento da criança com paralisia cerebral espástica. Rev. Bras. Cresc. Des. Hum. S. Paulo, 14(3), 2004. DOI: https:// doi.org/10.7322/jhgd.40114. Disponível em: https://www.revistas.usp.br/jhgd/article/ view/40114/42980. Acesso em: 19 abril 2019.

PRENSKY, Marc R. Teaching digital natives: partnering for real learning. [S.I] : Corwin Press, 2010. 224 p.

ROTTA, N T; BRIDI FILHO, C A, BRIDI, F R S (Org.). Plasticidade cerebral e aprendizagem. abordagem multidisciplinar. São Paulo : Artmed. 2018.

SANTOS, Coco dos Santos; CHIOTE, Fernanda de Araújo Binatti. Solicitude pedagógica e ato responsável: algumas reflexões sobre o aluno com autismo no ensino comum. SEMINÁRIO NACIONAL DE EDUCAÇÃO ESPECIAL E DO SEMINÁRIO CAPIXABA DE EDUCAÇÃO INCLUSIVA, 2016. Anais... Disponível em: http://www.periodicos.ufes.br/SNEE/article/view/24168/16534. Acesso em: 21 abril 2019.

SCHWARTZ, Gisele Maria (ORG.). Dinâmica lúdica : novos olhares. São Paulo : Manole. 2014.

TORRES, Patrícia Lupion; ALCANTARA, Paulo R.; IRALA, Esrom Adriano Freitas. grupos de consenso: uma proposta de aprendizagem colaborativa para o processo de ensino-aprendizagem. Revista Diálogo Educacional, Curitiba, v. 4, n.13, p.129145, set./dez. 2004. Disponível em: https://periodicos.pucpr.br/index.php/ dialogoeducacional/article/view/7052/6932. Acesso em: 19 abril 2019.

VYGOTSKY, L. S. Pensamento e linguagem - Edição Ridendo Castigat Mores Versão para eBook eBooksBrasil.com. 2007. Edição eletrônica: Ed Ridendo Castigat Mores. Disponível em: http://bibliotecadigital.puc-campinas.edu.br/services/e-books/ Lev\%20Semenovich\%20Vygotsky-1.pdf. Acesso em: 11 fev. 2019. 